\title{
GH10 xylanase D from Penicillium funiculosum: biochemical studies and xylooligosaccharide production
}

\author{
Mickael Lafond ${ }^{1}$, Alexandra Tauzin', Véronique Desseaux', Estelle Bonnin², El-Hassan Ajandouz ${ }^{1}$ and \\ Thierry Giardina ${ }^{1 *}$
}

\begin{abstract}
Background: The filamentous fungus Penicillium funiculosum produces a range of glycoside hydrolases (GH). The XynD gene, encoding the sole P. funiculosum GH10 xylanase described so far, was cloned into the pPICZaA vector and expressed in methylotrophe yeast Pichia pastoris, in order to compare the results obtained with the P. funiculosum GH11 xylanases data.
\end{abstract}

Results: High level expression of recombinant XynD was obtained with a secretion of around $60 \mathrm{mg} . \mathrm{L}^{-1}$. The protein was purified to homogeneity using one purification step. The apparent size on SDS-PAGE was around $64 \mathrm{kDa}$ and was $46 \mathrm{kDa}$ by mass spectrometry thus higher than the expected molecular mass of $41 \mathrm{kDa}$. The recombinant protein was $\mathrm{N}$ - and O-glycosylated, as demonstrated using glycoprotein staining and deglycosylation reactions, which explained the discrepancy in molecular mass. Enzyme-catalysed hydrolysis of low viscosity arabinoxylan (LVAX) was maximal at pH 5.0 with $\mathrm{Km}_{\text {(app) }}$ and $k_{\text {cat }} / \mathrm{Km}_{\text {(app) }}$ of $3.7 \pm 0.2\left(\mathrm{mg} \cdot \mathrm{mL}^{-1}\right)$ and $132\left(\mathrm{~s}^{-1} \mathrm{mg}^{-1} \cdot \mathrm{mL}\right)$, respectively. The activity of XynD was optimal at $80^{\circ} \mathrm{C}$ and the recombinant enzyme has shown an interesting high thermal stability at $70^{\circ} \mathrm{C}$ for at least $180 \mathrm{~min}$ without loss of activity. The enzyme had an endo-mode of action on xylan forming mainly xylobiose and short-chain xylooligosaccharides (XOS). The initial rate data from the hydrolysis of short XOS indicated that the catalytic efficiency increased slightly with increasing their chain length with a small difference of the XynD catalytic efficiency against the different XOS.

Conclusion: Because of its attractive properties XynD might be considered for biotechnological applications. Moreover, XOS hydrolysis suggested that XynD possess four catalytic subsites with a high energy of interaction with the substrate and a fifth subsite with a small energy of interaction, according to the GH10 xylanase literature data.

Keywords: xylanase GH10, Penicillium funiculosum, xylooligosaccharides

\section{Introduction}

Xylanases (endo-1,4- $\beta$-xylanases; EC 3.2.1.8) catalyze the hydrolysis of $\beta-1,4$ bonds of xylan, the major hemicellulose component of the plant cell wall. According to the sequence-based glycoside hydrolase $(\mathrm{GH})$ classification (CAZy classification) [1], xylanases are mainly grouped into families 10 (GH10) and 11 (GH11) but they were also found in glycoside hydrolase families 5, 8 and 43 http://www.cazy.org. A GH7 enzyme from Penicillium

\footnotetext{
* Correspondence: thierry.giardina@univ-cezanne.fr

'Université Paul Cézanne, ISM2/BiosCiences UMR CNRS 6263 (Université Aix Marseille III/CNRS), service 342, Faculté des Sciences et Techniques SaintJérôme, 13397 Marseille Cedex 20, France Full list of author information is available at the end of the article
}

funiculosum with xylanase/cellobiohydrolase activities was also reported and called XynA. GH10 family contains plant, fungal and bacterial enzymes whereas the structurally unrelated GH11 family only includes fungal and bacterial enzymes [1-3]. Xylanases are used in many food and feed sectors such as additives for broiler feed, bread making, in separation processes of gluten from starch in wheat or other cereals gluten from starch, production of juice from fruits or vegetables, extracting more fermentable sugar from barley for brewing, etc [4-6]. Recently, the potential applications of xylanases for bioconversion of hemicellulosic materials to xylo-oligosaccharides (XOS) have gained popularity instead of acid hydrolysis which is
C Biomed Central 
not environmentally feasible [7-9]. XOS have been shown to impact on human health by reducing cholesterol level and precancerous lesions, improving the biological availability of calcium and exhibiting a positive effect on gut microbiota [10-12]. The latter positive effect should be due to the enhancement of the production of different prebiotic molecules like short chain fatty acids known to promote the growth of beneficial bacteria such as Lactobacillus or Bifidobacteria and to lowering the cecal $\mathrm{pH}$ value [13-15].

In addition to the health promoting effects, XOS are moderately sweet and stable over a wide range of $\mathrm{pH}$ and temperatures and have organoleptic characteristics that make them suitable for incorporation into foods $[16,17]$.

Lignocellulosic biomass degradation used for biotechnological XOS production, needs thermal treatments coupled to thermostable xylanases. Moreover, a large amount of hemicellulosic fraction is insoluble and need action of appropriate enzymes. So, researches concerning new xylanases acting on high temperatures and able to hydrolyze insoluble substrate remain topical.

The filamentous fungi Penicillium funiculosum secretes a lot of glycosidases and the recent sequencing of the P. funiculosum genome, allowed discriminating about 200 genes encoding proteins with potential glycosidase activity [18]. Among the glycosidases which could be used during biotechnological processes, different types of xylanases were purified and their genes have been cloned $[19,20]$. XynB (GH11) and XynC (GH11) were recently extensively studied $[21,22]$ whereas little is known concerning XynD the only GH10 member family found to date in this microorganism [20]. GH10 xylanases typically exhibit a molecular weight $\geq 30 \mathrm{kDa}$ and a low $\mathrm{p} I$ [23]. The crystal structures of several GH10 enzymes showed that the catalytic domain is an 8 -fold $\alpha / \beta$-barrel forming a 'salad bowl'. Often, one or more extra domains are present, corresponding to carbohydrate binding module (CBM1) which binds to cellulose [24].

The activity of GH10 xylanases on AXs produces shorter XOS than those produced by GH11 xylanases. The former can act near the substituted xylose residue whereas the latter are bothered by additional groups like 4-O-methyl-D glucuronate, acetate and $\alpha$-L-arabinofuranose, thus restricting the access to the $\beta$-1,4-linkages in the xylan backbone [25]. It is worth noting that in the GH10 family, the members are able to produce different end-products due to the difference in their catalytic site [26].

Here we report the molecular characterization of XynD from Penicillium funiculosum encoding a $41 \mathrm{kDa}$ GH10 xylanase (XynD). The cDNA cloning and heterologous expression of XynD in Pichia pastoris was performed, and biochemical properties of the recombinant protein were determined, notably showing a natural thermal resistance. The enzyme was also characterized under kinetic viewpoint using various short and long substrates, especially regarding the XOS liberation profile.

\section{Materials and methods Materials}

The pPICZaA expression vector and the P. pastoris expression kit used, including the $P$. pastoris strain $\mathrm{X}-33$, zeocin, oligonucleotides and all restriction DNA modifying enzymes (except DNA polymerase) were from Invitrogen (Groningen, Netherlands). PrimeSTAR ${ }^{\mathrm{TM}} \mathrm{HS}$ DNA polymerase for polymerase chain reactions (PCR) was from Takara (Madison, USA). Escherichia coli DH5 $\alpha$ (supE44, hsdR17, recA1, endA1, gyrA96, thi-1, and relA1) was used for the DNA procedures (Invitrogen). Sodium phosphate and citric acid was from SigmaAldrich and Sephacryl S200 HR 26/60 chromatographic columns were from Amersham-Pharmacia Biotech (Uppsala, Sweden). Ultracel ${ }^{\mathrm{TM}}$ system and Ultracel ${ }^{\mathrm{TM}}$ PES membrane were from Millipore (Billerica, USA). The XynD concentration was determined by the Bradford method (1976) using the "Protein Assay" Reagent from Bio-Rad (Marnes-La-Coquette, France) [27].

\section{Cloning, expression and purification of XynD}

cDNA encoding XynD was synthesized by Geneart (Germany) using the GenBank AJ634957.1 accession number. The pPICZ $\alpha$ A-derived Pichia pastoris expression plasmid with the cDNA insert encoding XynD was constructed using standard procedures. The insert was purified using the QIAquick ${ }^{\circledR}$ (QIAGEN) purification kit and ligated into the XhoI/XbaI pPICZaA plasmid, which was digested with PmeI to linearize the DNA for integration into P. pastoris genome. The linearized DNA was used for electroporation into $P$. pastoris strain X-33 using a Multiporator ${ }^{\circledR}$ (Eppendorf) at $1500 \mathrm{~V}$ for $5 \mathrm{~ms}$. The transformants were selected using Minimal Methanol and Minimal Dextrose plates. Finally, in order to select multicopy vector strain transformants YPDS plates containing 100, 200, 500 and $1000 \mu \mathrm{g} / \mathrm{mL}$ zeocin ${ }^{\circledR}$ were used.

Large-scale expression was carried out as previously described [21]. The culture supernatant was concentrated using Ultracel ${ }^{\mathrm{TM}}$ PES ultrafiltration membrane $(3 \mathrm{kDa})$ and subjected to gel filtration at a flow rate of $1.5 \mathrm{~mL} \cdot \mathrm{min}^{-1}$ on a Sephacryl S-200 column connected to FPLC $^{\circledR}$ equipment (Akta Purifier 10, GE Healthcare, Piscataway, USA) and eluted with $50 \mathrm{mM}$ Na-phosphate buffer, $\mathrm{pH} 7.2$, containing $150 \mathrm{mM} \mathrm{NaCl}$. The fractions containing xylanases activity were pooled. 
Polyacrylamide gel electrophoresis, glycosylation staining, $\mathrm{N}$-terminal sequencing, molecular mass determination, and mass spectrometry analysis

SDS-PAGE was performed in 10 or $12 \%(\mathrm{w} / \mathrm{v})$ polyacrylamide gel in the presence of $2 \%$ SDS under reducing or non-reducing conditions [28]. Proteins were visualized by Coomassie blue R-250 staining. For glycosylation determination, SDS- polyacrylamide gel were stained for carbohydrate with periodic acid-Schiff (PAS) using a SIGMA glycoprotein staining kit $^{\circledR}$ according to the manufacturer's protocol.

$\mathrm{N}$-terminal amino acid sequencing of the Ponceau red stained protein after electro-transfer on a polyvinylidene difluoride membrane was performed by automated repetitive Edman degradation on a model 494 Procise $^{\mathrm{TM}}$ Protein Sequencer (Applied Biosystems Division) [29]. Molecular mass determination was performed by Matrix-assisted laser desorption ionization/mass spectrometry (Ettan Maldi-Tof Pro, GE Healthcare, Uppsala, Sweden) as previously described [21].

\section{Deglycosylation assay}

Purified XynD was N-deglycosylated using endo- $\beta$-acetylglucosaminidase H (Endo-H, Sigma Chemical Co.) and/or $\alpha$-mannosidase from Canavalia ensiformis (Sigma Chemical Co.). Treatment with Endo-H was carried out in a $10 \mathrm{mM}$ sodium citrate buffer, $\mathrm{pH}$ 5.0, for $6 \mathrm{~h}$ at $37^{\circ} \mathrm{C}$, with a ratio of $1000 \mathrm{U}: 77.5 \mu \mathrm{g}$ native and denaturated enzyme following the supplier recommendations. For O-deglycosylation, N-deglycosylated XynD was treated with $\alpha$-mannosidase in a $50 \mathrm{mM}$ sodium phosphate buffer, $\mathrm{pH} 6.0$ for $16 \mathrm{~h}$ at $37^{\circ} \mathrm{C}$, with a ratio of $14.2 \mathrm{U}: 60 \mu \mathrm{g}$ protein.

\section{Enzyme assays and effect of temperature and $\mathrm{pH}$ on enzyme activity}

Xylanase activity was measured using the dinitrosalicylic acid (DNS) assay. Aliquot of the xylanase $(10 \mu \mathrm{L})$ was mixed with $10 \mathrm{mg} \cdot \mathrm{mL}^{-1}$ low viscosity AX from wheat (LVAX) (Megazyme) in McIlvaine's buffer, pH 5.0 (total volume reaction volume $250 \mu \mathrm{l}$ ) at $70^{\circ} \mathrm{C}$ for $2 \mathrm{~min}$. The reaction was stopped by the addition of $250 \mu \mathrm{l}$ DNS reagent before boiling the mixture during $5 \mathrm{~min}$. The reactions were cooled and centrifuged for $3 \mathrm{~min}$ at $17000 \mathrm{~g}$ and $200 \mu \mathrm{L}$ was transferred to a microplate and the absorption was measured at $545 \mathrm{~nm}$. One unit (U) of xylanase activity was defined as the amount of protein that released $1 \mu \mathrm{mol}$ of xylose $\mathrm{min}^{-1}$, based on xylose calibration curve. Optimal $\mathrm{pH}$ for xylanase activity was estimated using the DNS assay with LVAX $\left(10 \mathrm{mg} \cdot \mathrm{mL}^{-1}\right)$ in McIlvaine's buffer in a $\mathrm{pH}$ range of 2.0 to 8.0. Optimal temperature was also estimated using the same xylanase assay with LVAX (10 mg. $\left.\mathrm{mL}^{-1}\right)$ in Mcllvaine's buffer at $\mathrm{pH} 5.0$ and temperatures ranging from $20^{\circ} \mathrm{C}$ to $100^{\circ} \mathrm{C}$.
Thermal stability was performed at $\mathrm{pH} 5.0$ and $70^{\circ} \mathrm{C}$ or $80^{\circ} \mathrm{C}$ for different time periods before performing activity assay.

\section{Determination of substrate specificity and kinetic parameters}

The substrate specificity of purified recombinant XynD was evaluated using the following substrates at $10 \mathrm{mg} \cdot \mathrm{mL}^{-}$ ${ }^{1}$ in McIlvaine's buffer, $\mathrm{pH}$ 5.0: LVAX, medium viscosity AX (MVAX, Megazyme), high viscosity AX (HVAX, Megazyme), water-insoluble AX (IAX, Megazyme), Birchwood Xylan (Sigma), Beechwood Xylan (Sigma), xyloglucan from tamarind (XGT, Megazyme). Water-extractable wheat AX with different ratio arabinose:xylose were prepared by sequential precipitation with $30 \%, 50 \%$ and $60 \%$ ethanol (AXMF30, AXMF50, AXMF60), [30]. Their A/X values were $0.33,0.53$ and 0.73 , respectively. Activity was measured by the DNS assay as described above.

Determinations of kinetic parameters were realized using the same condition described previously with LVAX as the substrate. Six concentrations of LVAX (2.5-20 mg. $\left.\mathrm{mL}^{-1}\right)$ were used. The final concentration of XynD was $1.6 \mathrm{nM}$. The reaction was stopped at appropriate time intervals $(2,4,6,8$ and $10 \mathrm{~min})$ and the initial rates of hydrolysis of LVAX have been determined accordingly and expressed as $\mu \mathrm{M}$ xylose/min. All experiments were repeated three times. Kinetic analyses were performed using the Michaelis-Menten, LineweaverBurk, Eadie-Hofstee and Dixon plots.

\section{XOS analysis and quantification}

Xylooligosaccharides and their products generated after XynD hydrolysis were analysed by high performance anion exchange chromatography coupled with a pulsed amperometric detection (HPAEC-PAD; Dionex, Sunnyvale, CA, USA) equipped with a Carbo-Pac PA-100 analytical column $(250 \times 4 \mathrm{~mm})$, a GP40 gradient pump, and a AS3500 auto-sampler (Thermo-Electron). The protocol used is the same as described by Cervera-Tison et al, in 2009 excepted for the composition of buffer A (NaOAC, $5 \mathrm{mM}$; $\mathrm{NaOH}, 80 \mathrm{mM}$ ) [31]. To evaluate the activity of the XynD on XOS (xylohexaose, xylopentaose, xylotetraose and xylotriose), initial slopes of progress curves were used to determine the catalytic efficiency $\left(k_{\text {cat }} / K \mathrm{~m}\right)$ of the reaction following the equation of Matsui as previously described by Cervera-Tison et al, in 2009 [31]. All assays were carried out in duplicate.

\section{Results and discussion \\ Characterization of $X y n D$ gene}

The $X y n D$ cDNA is predicted to encode a modular mature protein of 390 amino acid residues, which includes a 317 amino acid catalytic module, a 38 amino acid Ser/Thr rich linker and a 35 amino acid carbohydrate binding module 
with significant similarity to the carbohydrate binding module characteristic of fungal CBM1 [24]. Deduced molecular mass and $\mathrm{pI}$ of XynD were calculated to be $41540 \mathrm{Da}$ and 5.02, respectively. One N-glycosylation site was detected, at position N101, using NetNGlyc 1.0 Server and the DictyOGlyc server proposed several potential O-glycosylation sites (Figure 1).

A BLAST search showed that XynD shares highest amino acid sequence identity of 87 and $86 \%$ with family 10 xylanases from Talaromyces stipitatus and Penicillium marneffei, respectively (data not shown). This result together with biochemical characteristics, suggested that XynD, belongs to GH10 family, confirming the results from Furniss et al. in 2005 [20].

\section{Expression, purification and biochemical characterization of XynD}

In order to study the biochemical properties of the xylanase from $P$. funiculosum, the $X y n D$ cDNA was cloned into the pPICZ $\alpha$ A plasmid and expressed in Pichia pastoris as a recombinant protein using the native Saccharomyces cerevisiae $\alpha$-factor secretion signal sequence under the control of the AOX1 promoter. After an induction step with methanol, a major protein band with an apparent molecular mass of $64 \mathrm{kDa}$, which was not present in the supernatant of untransformed cells, was observed in the culture filtrate after SDS-PAGE analysis (data not shown). The amount of the $64 \mathrm{kDa}$ protein increased with time of induction (data not shown). Only trace amounts of other proteins were present in the culture supernatant. XynD was purified to homogeneity as described in the Materials and Methods section, giving a single peak after chromatography on a Sephacryl S200 gel containing 21\% of the supernatant activity. Thus, the enzyme was purified 1.9 fold with a specific activity of 33.9 U.mg ${ }^{-1}$.

The $\mathrm{N}$-terminal sequence EAEAQAQ was in complete agreement with that expected from the recombinant protein, EAEA corresponding to the $\mathrm{C}$-terminal end of the $\alpha$-factor signal peptide of pPICZ $\alpha$ A vector after efficient peptidase signal digestion (Kex2), followed by QAQ from XynD N-terminal mature sequence. The purified

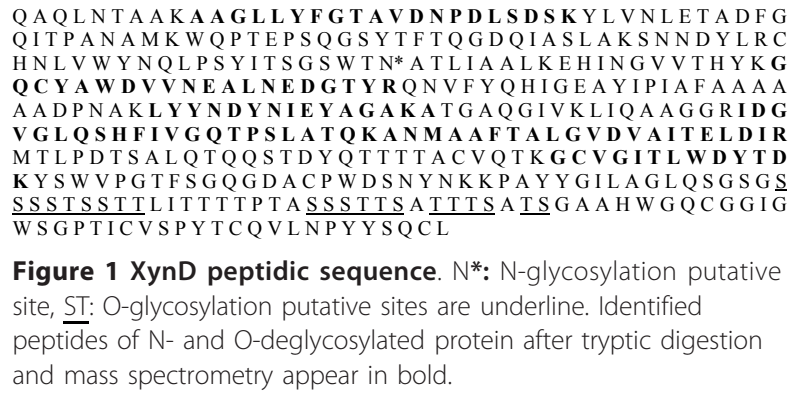

Figure 1 XynD peptidic sequence. $N^{*}$ : N-glycosylation putative site, ST: O-glycosylation putative sites are underline. Identified peptides of $\mathrm{N}$ - and $\mathrm{O}$-deglycosylated protein after tryptic digestion and mass spectrometry appear in bold.

recombinant enzyme migrated in SDS-PAGE give a single band around $64 \mathrm{kDa}$ (Figure 2, lane 2). The estimated size on electrophoresis gel and the $46 \mathrm{kDa}$ molecular mass determinate by mass spectrometry, thus much higher than the theoretical size of $41540 \mathrm{Da}$, suggesting that the recombinant XynD was glycosylated. The presence of sugars linked to the protein was confirmed by periodic acid Schiff staining (Figure 2, lane 6). One N-glycosylation site is present in XynD amino acid sequence at position N101, suggesting that $\mathrm{N}$-glycosylation is responsible for the higher molecular mass. To confirm this change was due to glycosylation, deglycosylation analysis was performed. After treatment with Endo $\mathrm{H}$ to remove $\mathrm{N}$-linked carbohydrate moieties, only a single band located at about $60 \mathrm{kDa}$ was observed (Figure 2, lane 3) which confirms that XynD was N-glycosylated. However, the molecular mass was still higher than that expected and periodic acid Schiff staining still positive, suggesting the presence of $\mathrm{O}-$ glycosylated moieties (Figure 2, lane 7). Actually, linker peptide connecting catalytic and carbohydrate-binding modules in fungal glycoside hydrolases are rich in Ser and Thr residues, and they are often $O$-glycosylated [32].

Thus, $\alpha$-mannosidase treatment was performed to remove O-glycosylated sugars and a band with a molecular mass around $43 \mathrm{kDa}$ appeared, corresponding to theoretical molecular mass of XynD and the deglycosylated enzyme was not stained by periodic acid Schiff (Figure 2, lane 4 and 8 ). Tryptic digestion and mass spectrometry analysis of the $\mathrm{N}$ - and $\mathrm{O}$-deglycosylated $43 \mathrm{kDa}$ protein confirmed that enzyme is XynD (Figure 1). A large amount of polymeric $\alpha$-mannosidase which gave 2

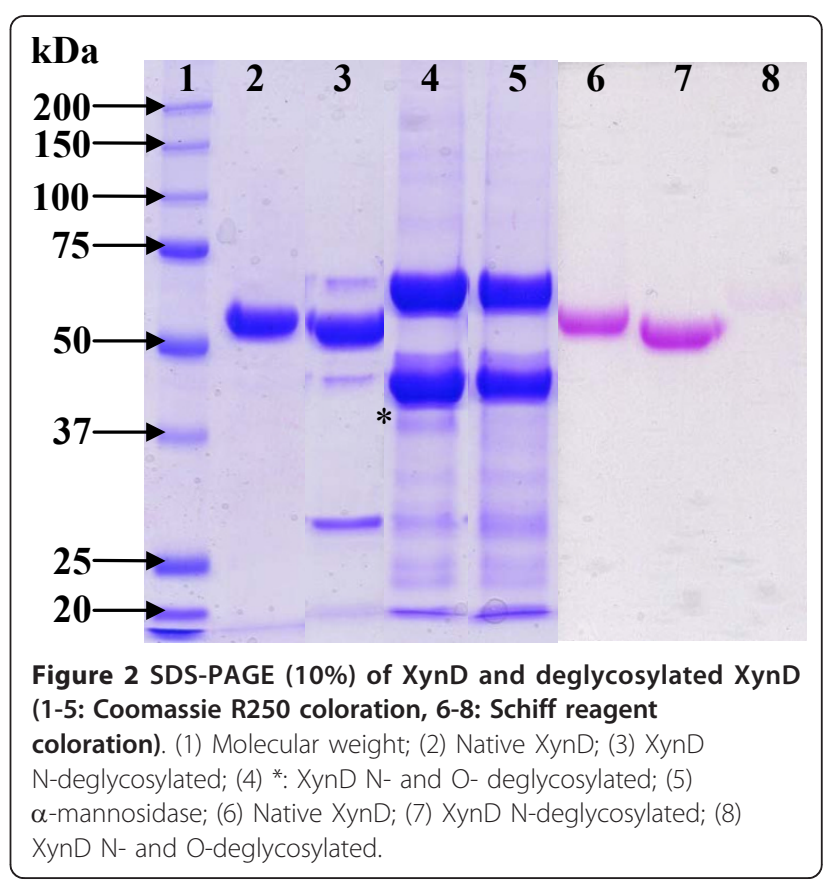


different bands around 44 and $66 \mathrm{kDa}$ (Figure 2, Lane 5) was necessary to totally O-deglycosylated XynD.

The experimental pI determined by isoelectrofocusing was 5.9 (data not shown). This result and the experimentally determined molecular mass were in good agreement with data collected in the literature. It is worth noting that almost all basic xylanases having a molecular mass of less than $30 \mathrm{kDa}$ belong to GH11 family, whereas acid xylanases have a molecular mass higher than $30 \mathrm{kDa}$ and belong to GH10 family [33].

\section{Effect of temperature and pH on XynD activity}

The effects of $\mathrm{pH}$ and temperature on the enzymatic activity were investigated on the recombinant enzyme. XynD displayed optimum activity in the 4.0 to $5.5 \mathrm{pH}$ range whereas the activity was lost at $\mathrm{pH} 2.5$ (Figure 3A).
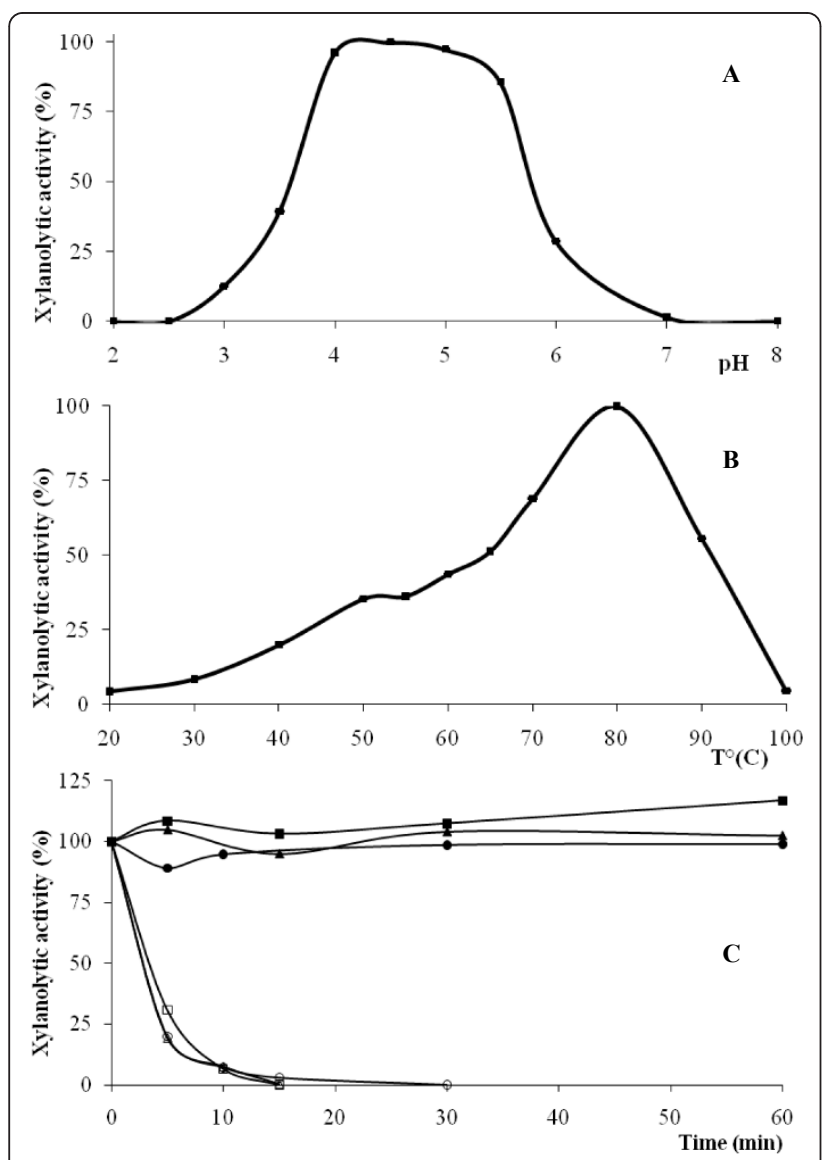

Figure $3 \mathrm{pH}(\mathrm{A})$ and temperature (B) optima and thermostability (C) of XynD from $P$. funiculosum. (A) Effect of $\mathrm{pH}$ on the activity. Enzyme activity was assayed in a pH range of 2.0-8.0. (B) Effect of temperature on the activity. Enzyme activity was assayed at various temperatures of $20-100^{\circ} \mathrm{C}$ in $100 \mathrm{mM}$ Mcllvaine's buffer ( $\mathrm{pH}$ 5.0). (C) Thermal stability of the enzyme. Thermal stability of the enzyme native (square) $\mathrm{N}$-deglycosylated (triangle), $\mathrm{N}$ - and O-deglycosylated (circle) at $70^{\circ} \mathrm{C}$ (full symbol) and $80^{\circ} \mathrm{C}$ (empty symbol) were measured after incubation during several minutes at $\mathrm{pH}$ 5.0.
At $\mathrm{pH} 5.0$, the optimal enzymatic activity was observed at $80^{\circ} \mathrm{C}$ whereas the activity drastically decreased above $90^{\circ} \mathrm{C}$ (Figure $3 \mathrm{~B}$ ). The thermal stability of the enzyme was determined at 70 and $80^{\circ} \mathrm{C}$ at the same $\mathrm{pH}$ value (Figure $3 \mathrm{C}$ ). XynD enzymatic activity decreases about $80 \%$ after $10 \mathrm{~min}$ at $80^{\circ} \mathrm{C}$ in contrast $\mathrm{XynD}$ is stable at least one hour at $70^{\circ} \mathrm{C}$. The high stability of XynD at $70^{\circ} \mathrm{C}$ should be highly useful for industrial purposes. This could be due to post-translational modifications of xylanase during excretion process, such as glycosylation. However, deglycosylated enzyme treated as above was found to be as stable as the glycosylated enzyme, suggesting that glycosylation had no effect on thermal stability.

\section{Substrate specificity of XynD from $P$. funiculosum}

The hydrolytic activity of XynD from $P$. funiculosum on various substrates was determined (Table 1). The enzyme showed a high specificity and a insensitivity towards different soluble xylans tested with specific activities ranging between $50.5 \pm 0.5{\mathrm{U} . \mathrm{mg}^{-1}}^{-1}$ for Birchwood Xylan and $114.3 \pm 1.0 \mathrm{U}^{\mathrm{mg}}{ }^{-1}$ for HVAX. The rate of insoluble xylan degradation was similar to that of soluble xylan degradation and XynD seemed to be a few sensitive to the xylan substitution degree with specific activities ranging between $80.6 \pm 1.8{\mathrm{U} . \mathrm{mg}^{-1}}^{-}$for AXMF60 and $120.8 \pm 1.6{\mathrm{U} . \mathrm{mg}^{-1}}^{-1}$ for AXMF30. The equivalent results were previously observed for the GH10 xylanase from Aspergillus aculeatus [34]. Because it is well-known that GH10 xylanases are preferentially active against soluble substrates, this result is very interesting, suggesting an important role of the CBM to hydrolyze the insoluble and viscous xylans during XynD action [35]. This would be highly useful for degradation of cell wall polysaccharides allowing easier access to starchy materials in cereals or other starch-rich grains. Finally, low activity was detected using xyloglucan as substrate.

Table 1 Specific activities (U.mg ${ }^{-1}$ ) of XynD on different substrates

\begin{tabular}{lll}
\hline Substrates & Specific Activity $\left(\mathbf{U} \cdot \mathbf{m g}^{-1}\right)$ & SD \\
\hline LVAX & 97.9 & 8.5 \\
MVAX & 106.4 & 0.2 \\
HVAX & 114.3 & 1.0 \\
IAX & 85.7 & 5.7 \\
Birchwood X & 50.5 & 0.5 \\
Beechwood X & 60.1 & 0.5 \\
AXMF30 & 120.8 & 1.6 \\
AXMF50 & 89.4 & 2.8 \\
AXMF60 & 80.6 & 1.8 \\
XGT & 0.9 & 0.1 \\
\hline
\end{tabular}

SD: standard deviation. 
Table 2 Kinetic values for XynD with LVAX as substrate and comparison with the $P$. funiculosum family 11 xylanases

\begin{tabular}{llllll}
\hline Enzyme & Plot & $\begin{array}{l}\boldsymbol{K}_{\mathbf{m}(\mathbf{a p p})} \\
\left(\mathbf{m g} \cdot \mathbf{m L}^{-1}\right)\end{array}$ & $\begin{array}{l}\boldsymbol{k}_{\text {cat }} \\
\left(\mathbf{s}^{-1}\right)\end{array}$ & $\begin{array}{l}\boldsymbol{k}_{\text {cat }} / \boldsymbol{K}_{\mathbf{m}(\mathbf{a p p})} \\
\left(\mathbf{s}^{-1} \mathbf{m g}^{-1} \cdot \mathbf{m L}\right)\end{array}$ & References \\
\hline XynD & M.M. & $3.7 \pm 0.2$ & 399 & 108 & This study \\
XynD & L.-B. & $5.0 \pm 0.2$ & 833 & 167 & $"$ \\
XynD & E.H. & $3.9 \pm 0.2$ & 523 & 134 & $"$ \\
XynB & M.-M. & $40.0 \pm 3.0$ & 5405 & 135 & {$[21]$} \\
XynC & M.-M. & $14.4 \pm 0.7$ & 2939 & 204 & {$[22]$}
\end{tabular}

For $\mathrm{XynD}$, the parameters were determined from primary plots of MichaelisMenten (M.-M), Lineweaver-Burk (L.B) and Eadie-Hofstee (E.-H) plots.

\section{Determination of kinetic parameters}

The XynD-catalysed hydrolysis of LVAX was measured with the optimal temperature $\left(70^{\circ} \mathrm{C}\right)$ and $\mathrm{pH} 5$ conditions (Table 2). The experimental initial rates were used for determination of $k_{\text {cat }}$ and $K \mathrm{~m}_{(\mathrm{app})}$ and calculation of the catalytic efficiency, $k_{\text {cat }} / \mathrm{Km}_{(\text {(app) }}$ according the kinetic models of Michaelis-Menten, Lineweaver-Burk and Eadie-Hofstee (plot not shown). The $\mathrm{Km}_{(\mathrm{app})}$ of XynD with LVAX as the substrate is 3 to 8 fold higher than those of $P$. funiculosum GH11 xylanases but the catalytic efficiency $\left(k_{\text {cat } /} / \mathrm{m}_{\text {(app) }}\right)$ were similar [21,22].

In order to evaluate the mode of action of XynD, the products generated using highly polymeric substrates and on short substrates ranging from xylotetraose to xylohexaose were analysed by HPAEC-PAD. XynD displayed mainly an endo-activity against wheat AX (LVAX) because the XOS generated during the initial stages of hydrolysis were progressively degraded yielding principally xylobiose and to a lower extent of xylotriose and xylose (Figure 4). This characteristic is obviously similar to GH11 xylanases that yield xylobiose and xylotriose as main end reaction products $[22,31]$.

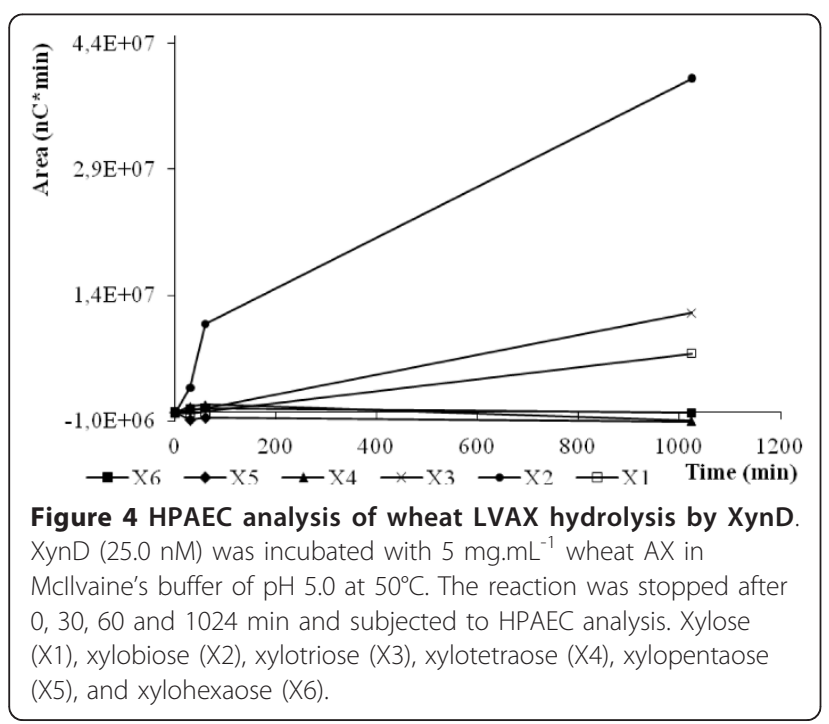

XynD exhibited an exclusive endo-mode of action against XOS. Indeed, xylohexaose was hydrolysed to xylotriose, xylotetraose and xylobiose; xylopentaose to xylobiose and xylotriose; whereas xylotetraose was cleaved to produce exclusively xylobiose (Figure 5). No significant amount of xylose was generated during hydrolysis of XOS. The catalytic efficiency $\left(k_{\mathrm{cat}} / \mathrm{Km}\right)$ increased slightly with increasing chain length of XOS up to $n=6$ (Table 3 ) and the relative value on xylotetraose, xylopentaose and xylohexaose, was 1:1.3:8.8. Xylanase C from $P$. funiculosum, a GH11 xylanase family, showed different catalytic efficiency $\left(k_{\text {cat }} / K \mathrm{~m}\right)$ results on the same substrates with the following relative values: 1:2.1:39.3 [22]. Finally, the most important
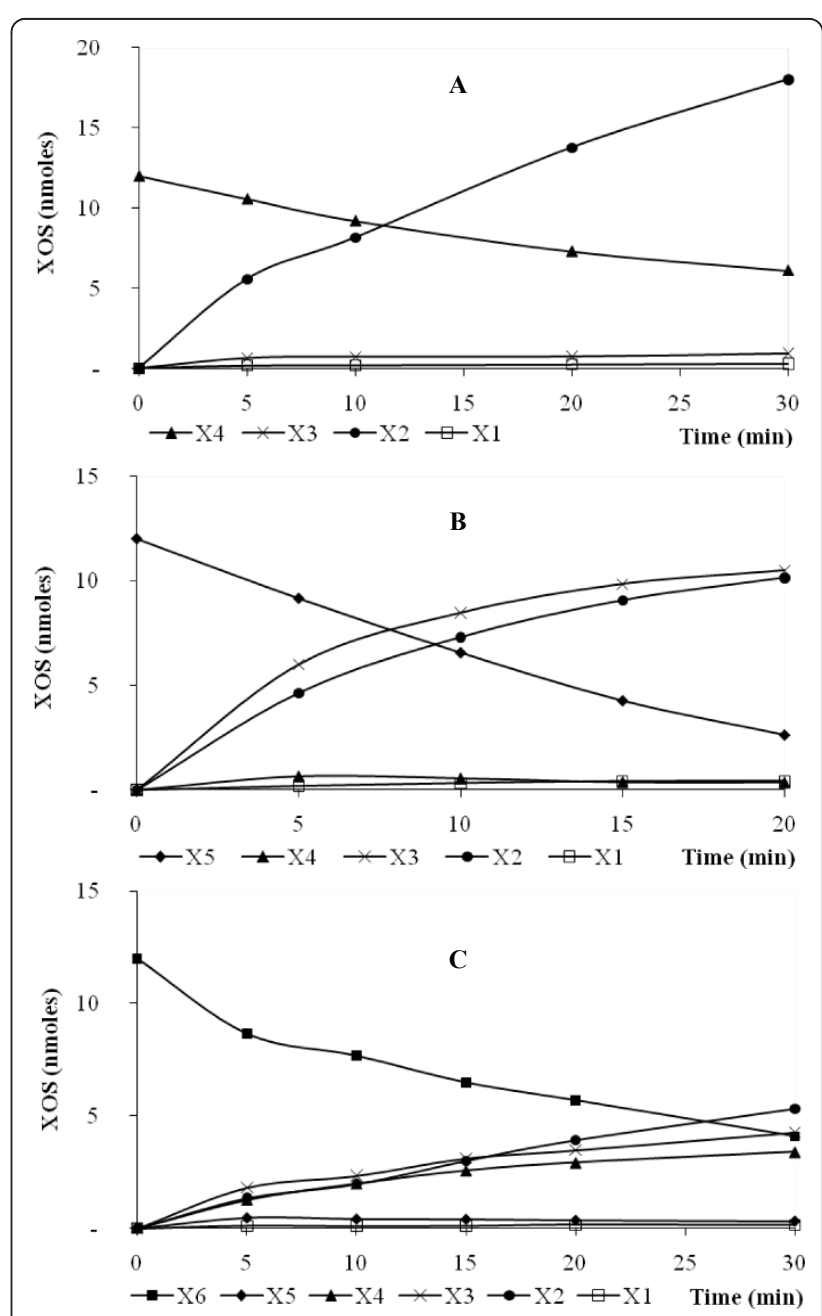

Figure 5 Progress curves of the XOS generated by XynD after hydrolysis of xylotetraose (A), xylopentaose (B), and xylohexaose (C). Recombinant enzymes were incubated with 100 $\mu \mathrm{M}$ of $\mathrm{XOS}$ in Mcllvaine's buffer $\mathrm{pH} 5.0$ at $70^{\circ} \mathrm{C}$. The quantity of xylose $(X 1)$, xylobiose $(X 2)$, xylotriose $(X 3)$, xylotetraose (X4), xylopentaose (X5), and xylohexaose (X6) produced during the course of the reaction is indicated. The concentrations of enzymes used were $640 \mathrm{nM}(\mathrm{A}), 16.1 \mathrm{nM}(\mathrm{B})$, and $6.4 \mathrm{nM}(\mathrm{C})$. 
Table 3 Catalytic efficiencies of XynD compared to 3 Penicillium sp. GH11 xylanases

\begin{tabular}{|c|c|c|c|}
\hline Enzymes & $\begin{array}{l}\text { Substrates } \\
(100 \mu \mathrm{M})\end{array}$ & $\begin{array}{l}k_{\text {cat }} / K m \\
\left(\min ^{-1} \cdot M^{-1}\right)\end{array}$ & References \\
\hline \multirow[t]{3}{*}{ XynD } & $x 6$ & $5.9 .10 \wedge 6$ & This study \\
\hline & $\times 5$ & $4.4 .10^{\wedge} 6$ & $"$ \\
\hline & $x 4$ & $1.5 .10^{\wedge} 6$ & $"$ \\
\hline \multirow[t]{3}{*}{ Xync } & $x 6$ & $6.5 .10^{\wedge} 6$ & {$[22]$} \\
\hline & $\times 5$ & $3.1 .10^{\wedge} 6$ & $"$ \\
\hline & $x 4$ & $1.8 .10 \wedge 5$ & $"$ \\
\hline \multirow[t]{3}{*}{ XynA } & $x 6$ & $2.6 .10^{\wedge} 6$ & {$[22]$} \\
\hline & $\times 5$ & $4.6 .10 \wedge 5$ & $"$ \\
\hline & $x 4$ & $3.0 .10 \wedge 4$ & $"$ \\
\hline \multirow[t]{3}{*}{$X y \cap B$} & $x 6$ & $8.0 .10 \wedge 5$ & [31] \\
\hline & $\times 5$ & $7.4 .10^{\wedge} 4$ & $"$ \\
\hline & $x 4$ & $6.2 .10 \wedge 3$ & $"$ \\
\hline
\end{tabular}

Xylohexaose (X6), xylopentaose (X5) and xylotetraose (X4) were used as substrates.

difference was found with XynB from $P$. griseofulvum 1:12:129 [31]. Both the studies concluded that these xylanases potentially contain six subsites in their active site. Xylohexaose degradation produced only xylotriose, indicating that the minimum length of the substrate is four residues. Moreover, the small difference of the XynD catalytic efficiency against xylotetraose and xylopentaose and against xylopentaose and xylohexaose suggest that XynD possess four catalytic subsites with a high energy of interaction with the substrate and a fifth subsite with a small energy of interaction. However this hypothesis will be confirmed by a modeling study.

\section{Conclusion}

Filamentous fungus P. funiculosum is known for its capacity to produce xylanases with different capacities that may provide the fungus with the maximum potential to degrade xylans from different sources. In this study, the P. funiculosum GH10 unique gene encoding a xylanase was cloned and express in $P$. pastoris yeast. Biochemical characterization and enzymatic analysis showed that XynD presented a high temperature optimal for hydrolysis activity, was thermostable and it was a versatile xylanase in term of activities and catalytic efficiencies than the others $P$. funiculosum xylanases. Because of its attractive properties XynD might be considered for biotechnological applications.

\section{Abbreviations}

AX: arabinoxylan; AXMF: AXs with different ratio A/X; CBM: carbohydrate binding module; DNS: dinitrosalicylic acid; GH: glycoside hydrolase; HAVX: high viscosity AXs; HPAEC-PAD: high performance anion exchange chromatography; IAX: insoluble AXs; LVAX: Iow viscosity AXs; MAVX: medium viscosity AXs; PAS: periodic acid Schiff; PBS: phosphate-buffered saline; PES: polyether sulfone; XGT: xyloglucan; XOS: xylooligosaccharides.

\section{Author details}

'Université Paul Cézanne, ISM2/BiosCiences UMR CNRS 6263 (Université Aix Marseille III/CNRS), service 342, Faculté des Sciences et Techniques SaintJérôme, 13397 Marseille Cedex 20, France. ${ }^{2}$ INRA, UR 1268 - Biopolymères Interactions - Assemblages, 44316 Nantes Cedex 03, France.

\section{Authors' contributions}

ML was involved in study design, data interpretation and manuscript writing; AT was involved in biochemical and enzymatic analysis; VD was involved in biochemical analysis design and data interpretation; EB was involved in the determination of the activity assays and in the data interpretation; EHA was involved in data interpretation and manuscript writing; TG was the coordinator of the study design and was involved in data interpretation and manuscript writing and editing. All authors read and approved the final manuscript.

\section{Competing interests}

The authors declare that they have no competing interests.

Received: 15 December 2010 Accepted: 5 April 2011

Published: 5 April 2011

\section{References}

1. Henrissat B: A Classification of Glycosyl Hydrolases Based on Amino-AcidSequence Similarities. Biochem J 1991, 280:309-316.

2. Henrissat B, Bairoch A: New Families in the Classification of Glycosyl Hydrolases Based on Amino-Acid-Sequence Similarities. Biochem J 1993, 293:781-788.

3. Henrissat B, Bairoch $A$ : Updating the sequence-based classification of glycosyl hydrolases. Biochem J 1996, 316:695-696.

4. Subramaniyan S, Prema P: Biotechnology of microbial xylanases: Enzymology, molecular biology, and application. Crit Rev Biotechnol 2002, 22:33-64.

5. Beg QK, Kapoor M, Mahajan L, Hoondal GS: Microbial xylanases and their industrial applications: a review. Appl Microbiol Biot 2001, 56:326-338.

6. Techapun C, Poosaran N, Watanabe M, Sasaki K: Thermostable and alkalinetolerant microbial cellulase-free xylanases produced from agricultural wastes and the properties required for use in pulp bleaching bioprocesses: a review. Process Biochem 2003, 38:1327-1340.

7. Wong KKY, Saddler JN: Trichoderma Xylanases, Their Properties and Application. Crit Rev Biotechnol 1992, 12:413-435.

8. Bajpai P: Application of enzymes in the pulp and paper industry. Biotechnol Progr 1999, 15:147-157

9. Niehaus F, Bertoldo C, Kahler M, Antranikian G: Extremophiles as a source of novel enzymes for industrial application. Appl Microbiol Biot 1999 51:711-729.

10. Okazaki M, Fujikawa S, Matsumoto N: Effect of xylo-oligosaccharide on the growth of bifidobacteria. Bifidobact Microflora 1990, 9:77-86.

11. Campbell JM, Fahey GC, Wolf BW: Selected indigestible oligosaccharides affect large bowel mass, cecal and fecal short-chain fatty acids, $\mathrm{pH}$ and microflora in rats. J Nutr 1997, 127:130-136.

12. Madhukumar MS, Muralikrishna G: Structural characterisation and determination of prebiotic activity of purified xylo-oligosaccharides obtained from Bengal gram husk (Cicer arietinum L.) and wheat bran (Triticum aestivum). Food Chem 2010, 118:215-223.

13. Roberfroid MB: Health benefits of non-digestible oligosaccharides. In Dietary Fiber in Health and Disease. Edited by: Kritchevsky D, Bonfield Ch. New York: Plenum Press; 1997:211-219.

14. Hsu CK, Liao JW, Chung YC, Hsieh CP, Chan YC: Xylo-oligosaccharides and fructooligosaccharides affect the intestinal microbiota and precancerous colonic lesion development in rats. J Nutr 2004, 134:1523-1528.

15. Moure A, Gullon P, Dominguez H Parajo JC: Advances in the manufacture, purification and applications of xylo-oligosaccharides as food additives and nutraceuticals. Process Biochem 2006, 41:1913-1923.

16. Gibson GR, Roberfroid MB: Dietary Modulation of the Human Colonic Microbiota - Introducing the Concept of Prebiotics. J Nutr 1995, 125:1401-1412.

17. Barreteau H, Delattre C, Michaud P: Production of oligosaccharides as promising new food additive generation. Food Technol Biotech 2006, 44:323-333. 
18. Guais O, Borderies G, Pichereaux C, Maestracci M, Neugnot V, Rossignol M, Francois JM : Proteomics analysis of "RovabioTM Excel", a secreted protein cocktail from the filamentous fungus Penicillium funiculosum grown under industrial process fermentation. J Ind Microbiol Biot 2008 35:1659-1668

19. Furniss CSM, Belshaw NJ, Alcocer MJC, Williamson G, Elliott GO, Gebruers K, Haigh NP, Fish NM, Kroon PA: A family 11 xylanase from Penicillium funiculosum is strongly inhibited by three wheat xylanase inhibitors. Biochim Biophys Acta 2002, 1598:24-29.

20. Furniss CSM, Williamson G, Kroon PA: The substrate specificity and susceptibility to wheat inhibitor proteins of Penicillium funiculosum xylanases from a commercial enzyme preparation. J Sci Food Agr 2005, 85:574-582.

21. Brutus A, Villard C, Durand A, Tahir T, Furniss C, Puigserver P, Juge N, Giardina T: The inhibition specificity of recombinant Penicillium funiculosum xylanase B towards wheat proteinaceous inhibitors. Biochim Biophys Acta 2004, 1701:121-128.

22. Berrin JG, Ajandouz EH, Georis J, Arnaut F, Juge N: Substrate and product hydrolysis specificity in family 11 glycoside hydrolases: an analysis of Penicillium funiculosum and Penicillium griseofulvum xylanases. Appl Microbiol Biot 2007, 74:1001-1010

23. Torronen A, Rouvinen J: Structural and functional properties of low molecular weight endo-1,4-beta-xylanases. J Biotechnol 1997, 57:137-149.

24. Levasseur A, Navarro D, Punt PJ, Belaïch JP, Asther M, Record E: Construction of engineered bifunctional enzymes and their overproduction in Aspergillus niger for improved enzymatic tools to degrade agricultural by-products. Appl Environ Microb 2005, 71:8132-8140.

25. Beaugrand J, Chambat G, Wong WWK, Goubet F, Rémond C, Paës G: Impact and efficiency of GH10 and GH11 thermostable endoxylanases on wheat bran and alkali-extractable arabinoxylans. Carbohyd Res 2004, 339:2529-2540.

26. Pell G, Szabo L, Charnock SJ, Xie HF, Gloster TM, Davies GJ, Gilbert HJ: Structural and biochemical analysis of Cellvibrio japonicus xylanase $10 \mathrm{C}$ How variation in substrate-binding cleft influences the catalytic profile of family GH-10 xylanases. J Biol Chem 2004, 279:11777-11788.

27. Bradford MM: Rapid and Sensitive Method for Quantitation of Microgram Quantities of Protein Utilizing Principle of Protein-Dye Binding. Anal Biochem 1976, 72:248-254.

28. Laemmli UK: Cleavage of Structural Proteins During Assembly of Head of Bacteriophage-T4. Nature 1970, 227:680-685.

29. Matsudaira P: Sequence from picomole quantities of proteins electroblotted on to polyvinylidene difluoride membranes. J Biol Chem 1987, 262:10035-10038.

30. Dervilly G, Saulnier L, Roger P, Thibault JF: Isolation of homogeneous fractions from wheat water-soluble arabinoxylans. Influence of the structure on their macromolecular characteristics,. J Agr Food Chem 2000, 48:270-278.

31. Cervera-Tison MC, Andre-Leroux G, Lafond M, Georis J, Juge N, Berrin J-G : Molecular determinants of substrate and inhibitor specificities of the Penicillium griseofulvum family 11 xylanases. Biochim Biophys Acta 2009, 1794:438-445

32. Goto M: Protein O-glycosylation in fungi: Diverse structures and multiple functions. Biosci Biotech Bioch 2007, 71:1415-1427.

33. Wong KKY, Tan LUL, Saddler JN: Multiplicity of Beta-1,4-Xylanase in Microorganisms - Functions and Applications. Microbiol Rev 1988, 52:305-317.

34. Bonnin E, Daviet S, Sorensen JF, Sibbesen O, Goldson AJ, Juge N, Saulnier L: Behaviour of family 10 and 11 xylanases towards arabinoxylans with varying structure. J Sci Food Agr 2006, 86:1618-1622.

35. Maes C, Vangeneugden B, Delcour JA: Relative activity of two endoxylanases towards water-unextractable arabinoxylans in wheat bran. J Cereal Sci 2004, 39:181-186.

doi:10.1186/1475-2859-10-20

Cite this article as: Lafond et al:: GH10 xylanase D from Penicillium funiculosum: biochemical studies and xylooligosaccharide production. Microbial Cell Factories 2011 10:20

\section{Submit your next manuscript to BioMed Central and take full advantage of:}

- Convenient online submission

- Thorough peer review

- No space constraints or color figure charges

- Immediate publication on acceptance

- Inclusion in PubMed, CAS, Scopus and Google Scholar

- Research which is freely available for redistribution

Submit your manuscript at www.biomedcentral.com/submit
Biomed Central 